\title{
DETERMINAÇÃO DE CARGAS POLUIDORAS EM CURSOS D’AGUA DE MÉDIO PORTE
}

Rosane Freire ${ }^{1}$

Cássia Maria Bonifácio ${ }^{2}$

Roselene Maria Schneider ${ }^{3}$

RESUMO: O presente trabalho teve como objetivo verificar a qualidade das águas de um curso d'água de médio porte a partir da quantificação de cargas poluidoras. Para isso foram estabelecidos seis pontos de amostragem de qualidade de água e quatro postos fluviométricos que compreenderam cerca de dezenove quilômetros da bacia hidrográfica do ribeirão Maringá, localizado no município de Maringá-PR. A coleta das amostras foi realizada por meio de sete campanhas, no qual os seguintes parâmetros de qualidade foram analisados: sólidos totais, demanda bioquímica de oxigênio, coliformes termotolerantes, nitrato e fósforo total. Para a modelagem da vazão nos trechos de difícil acesso foi utilizado o modelo QUAL2E. A quantificação das cargas poluidoras foi determinada por meio do produto dos valores de concentração de poluentes pela vazão dos cursos d'água. Por meio dos resultados obtidos foi possível observar no que diz respeito à quantificação das cargas poluidoras, que estas apresentaram valores altíssimos para os parâmetros analisados e observou-se que o ribeirão Maringá vem recebendo um enorme aporte, tanto de sólidos quanto de matéria orgânica e nutrientes,

\footnotetext{
${ }^{1}$ Engenharia Ambiental, Mestre e Doutora em Engenharia Química. Universidade Estadual de Maringá. Email: rofreire@gmail.com

${ }^{2}$ Mestre em Geografia, Universidade Estadual de Maringá. Email: kaoruyuri@hotmail.com

${ }^{3}$ Professora Efetiva da Universidade Federal do Mato Grosso - Campus Universitário de Sinop. Email: roselenems@yahoo.com.br
} 
provenientes principalmente do tratamento não efetivo dos esgotos do município, do lançamento clandestino de esgotos, entre outras fontes de poluição provenientes das áreas urbanas, rurais e industriais.

Palavras-chave: Poluição. Características hidráulicas. Ribeirão Maringá.

\section{INTRODUÇÃO}

O Estado do Paraná, caminhando na perspectiva da efetivação do instrumento de gerenciamento de recursos hídricos, por meio da Política Estadual de Recursos Hídricos (Lei Estadual ㄲo. 12726/1999) e com criação dos Comitês Gestores de Bacias, vem incentivando o desenvolvimento de pesquisas que visem à recuperação de mananciais das unidades hidrográficas.

Algumas unidades já possuem seus estudos concluídos, os quais já permitiram a elaboração dos respectivos Planos de Bacia, como é o caso do Alto do Iguaçu e rio Ribeira, do rio Tibagi e do rio Jordão (PARANÁ, 2007). O Plano da Bacia Hidrográfica do Rio Pirapó, localizado na porção norte do Estado do Paraná, foi recentemente iniciado. A problemática que envolve esta área é que se trata um corpo d'água utilizado para abastecimento público, diluição e transporte de efluentes dos polos industriais da região Norte e Noroeste do Estado, além de ser um local com extensa atividade agrícola, com culturas de soja, milho e trigo.

A complexidade dos fatores ambientais que causam impactos por toda a bacia faz com que trabalhos locais sejam necessários para melhor avaliação da situação da área. Neste sentido, destacam-se os estudos voltados para os afluentes do rio Pirapó, entre eles, o ribeirão Maringá, que se encontra no município de Maringá - PR.

Algumas pesquisas já foram realizadas no ribeirão, no âmbito da concentração de sedimentos em suspensão (BIAZIN, 2003), da identificação de fontes poluidoras (PERUÇO, 2004), da indicação de fragilidade ambiental (SALA, 2010), da dinâmica fluvial e qualidade de água (COELHO, 2007), da caracterização da qualidade das águas, índice de qualidade de água, avaliação do transporte fluvial e erosão marginal (SCHINEIDER, 2011), entre outros. 


\section{Then Fórum Ambiental \\ da Alta Paulista

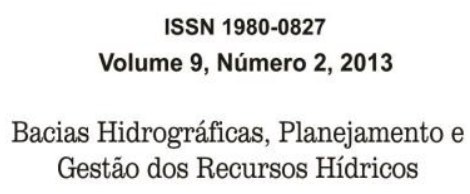

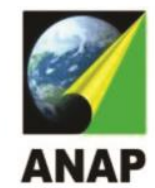

No entanto, até o momento, nenhum trabalho abordou o monitoramento sistemático das características de qualidade do ribeirão, frente à carga de poluição iaportada para 0 curso d'água de forma mais completa. Segundo Soares (2001), a manutenção da qualidade ambiental está diretamente relacionada ao conhecimento e controle das variáveis que interferem no problema, sejam elas resultantes das ações do homem sobre o ambiente ou de suas transformações naturais. Essa manutenção pode ser feita por meio do monitoramento de parâmetros físico-químicos e biológicos, conhecimento do comportamento hidráulico do corpo hídrico, de sua capacidade de assimilação de poluentes, quantificação de cargas poluidoras, entre outros.

Assim, o presente trabalho desenvolveu-se no sentido de verificar a qualidade das águas do ribeirão Maringá por meio da modelagem da vazão e quantificação de cargas poluidoras de modo a construir um banco de informações, organizadas espacialmente, que descreva de forma mais detalhada possível as características comportamentais das águas do ribeirão Maringá. Espera-se assim, subsidiar tecnicamente as ações a serem adotadas pelo Comitê de Bacia atuante e a manter a disponibilidade de água, qualitativa e quantitativamente, para os usos múltiplos pretendidos para a Bacia Hidrográfica do rio Pirapó.

\section{METODOLOGIA}

\subsection{Descrição da Área de Estudo e Localização dos Pontos de Amostragem}

A bacia do ribeirão Maringá (Figura 1 ) está localizada entre a latitude $23^{\circ} 16^{\prime} \mathrm{S}$ e $23^{\circ} 26^{\prime} \mathrm{S}$ e longitude $51^{\circ} 55^{\prime} \mathrm{W}$ e $52^{\circ} 00^{\prime} \mathrm{W}$, na região norte do município de Maringá $\mathrm{PR}$, pertencendo à unidade de gerenciamento da bacia do rio Pirapó. De acordo com Sala (2010), o clima da região determinado pelo método de Köppen é classificado como subtropical úmido mesotérmico (Cfa). A precipitação média anual varia entre $1250 \mathrm{~mm}$ a $1500 \mathrm{~mm}$, apresentando verões quentes e chuvosos, invernos com geadas pouco frequentes, sem estação seca definida. 


\section{Then Fórum Ambiental \\ da Alta Paulista}

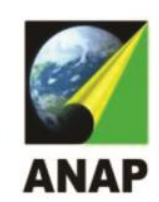

Segundo Borsato e Martoni (2004), a bacia em estudo possui cotas altimétricas que variam de $600 \mathrm{~m}$ a $375 \mathrm{~m}$, drena uma área de $90,37 \mathrm{~km}^{2}$ e possui aproximadamente 19 $\mathrm{km}$ de comprimento de leito, o que a caracteriza como de porte médio. Quanto à declividade, os valores variam de até $6 \%$ para os topos, de $6 \%$ a 12\% nas médias vertentes e entre $12 \%$ a $20 \%$ em áreas próximas aos canais de drenagem.

$\mathrm{Na}$ área de estudo, ainda de acordo com Sala (2010), predominam três tipos de solos: o latossolo vermelho férrico, os nitossolos vermelhos distroférricos e os neossolos flúvicos. O substrato geológico é, por sua vez, constituído por rochas vulcânicas básicas (basaltos) pertencentes à Formação Serra Geral, Grupo São Bento. O uso e ocupação do solo, descrito por Biazin (2003), caracteriza-se por apresentar 25,5\% de sua área ocupada pelo perímetro urbano (à montante da bacia); $26 \%$ por pastagens; 36 \% com culturas temporárias (soja/milho); 2 \% por solo exposto e 10,5\% por áreas de mata.

Para averiguar os fatores que influenciam a qualidade da água do ribeirão Maringá, de forma mais detalhada possível, foram propostos seis pontos de amostragem distribuídos por toda bacia, compreendendo desde sua nascente até a foz no Rio Pirapó (Figura 1). Estabeleceram-se um ponto no córrego Mandacaru (P1), um ponto no córrego Romeira (P2) e quatro pontos distribuídos ao longo do ribeirão Maringá (P3, P4, P5, P6). Esses pontos foram distribuídos tendo em vista a contribuição dos tributários sobre a qualidade da água, a proximidade das fontes poluidoras e a facilidade de acesso ao local.

Para o monitoramento fluviométrico foram estabelecidos quatro pontos, sendo um localizado no córrego Mandacaru (F1), um no córrego Romeira (F2) e os demais alocados no ribeirão Maringá (F4 e F6). Estes postos foram situados o mais próximo possível dos pontos de amostragem de água de forma a manter a devida correspondência de qualidade e vazão. 


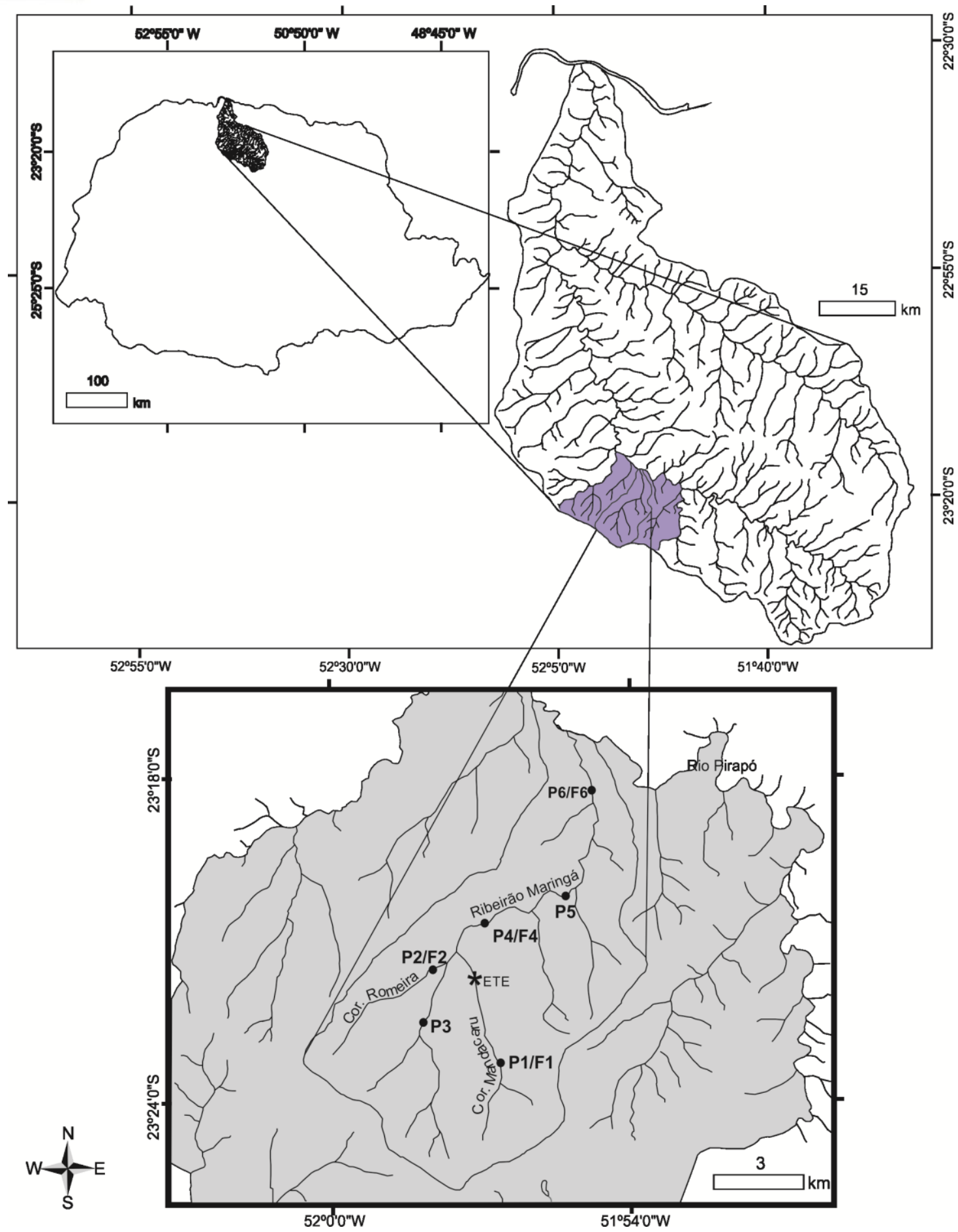

Figura 1. Localização da área de estudo e dos pontos de coleta.

\subsection{Parâmetros Qualidade Analisados}




\section{Then Fórum Ambiental \\ da Alta Paulista

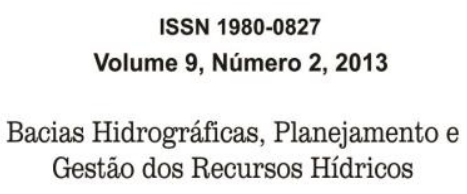

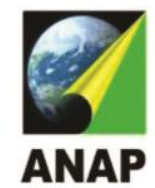

A coleta das amostras para determinação dos parâmetros de qualidade da água e cargas poluidoras foram realizadas em 7 campanhas, compreendendo o período de setembro de 2008 a agosto de 2009. Os trabalhos em campo foram realizados no período da manhã, de forma pontual, com amostragem simples no ponto central da seção do curso d'água As amostras foram armazenadas em frascos de polietileno (2L) e mantidas em resfriamento.

As análises foram realizadas no Laboratório de Gestão, Preservação e Controle Ambiental (LGPCA) do Departamento de Engenharia Química da Universidade Estadual de Maringá (UEM). Para garantir confiabilidade dos resultados obtidos, os testes foram executados em duplicata, possibilitando o cálculo do resultado médio.

Os parâmetros de qualidade analisados foram sólidos totais (ST), demanda bioquímica de oxigênio (DBO), nitrato $\left(\mathrm{NO}_{3}{ }^{-}\right)$, coliformes termotolerantes (CT) e fósforo total (FT), seguindo os procedimentos descritos em "Standard Methods for the Examination of Water and Wastewater" (APHA, 1998).

Trabalhos adicionais em campo foram realizados com finalidade investigativa. Os dados de precipitação pluviométrica dos meses estudados também foram coletados. Os dados foram fornecidos pela Estação Climatológica da Universidade Estadual de Maringá com o intuito de verificar a interferência das chuvas nos parâmetros qualitativos e hidráulicos nos dias das coletas.

\subsection{Determinação da Vazão}

As medidas de vazão foram determinadas por meio do medidor digital FlowTracker, da SONTEK ${ }^{\circledR}$. O equipamento de medição utiliza o método acústico (efeito Doppler) para quantificação da vazão e é recomendado para cursos d'água de médio e grande porte.

O método utiliza a relação velocidade e área da seção transversal para a determinação da vazão; assim, foi necessário estabelecer uma seção transversal de referência. Inicialmente foi obtida a largura da seção do trecho em estudo, com auxílio de uma trena. Em seguida, essa seção foi dividida em uma série de verticais igualmente 
separadas, onde foram medidas suas respectivas profundidades, conforme ilustra a Figura 2.

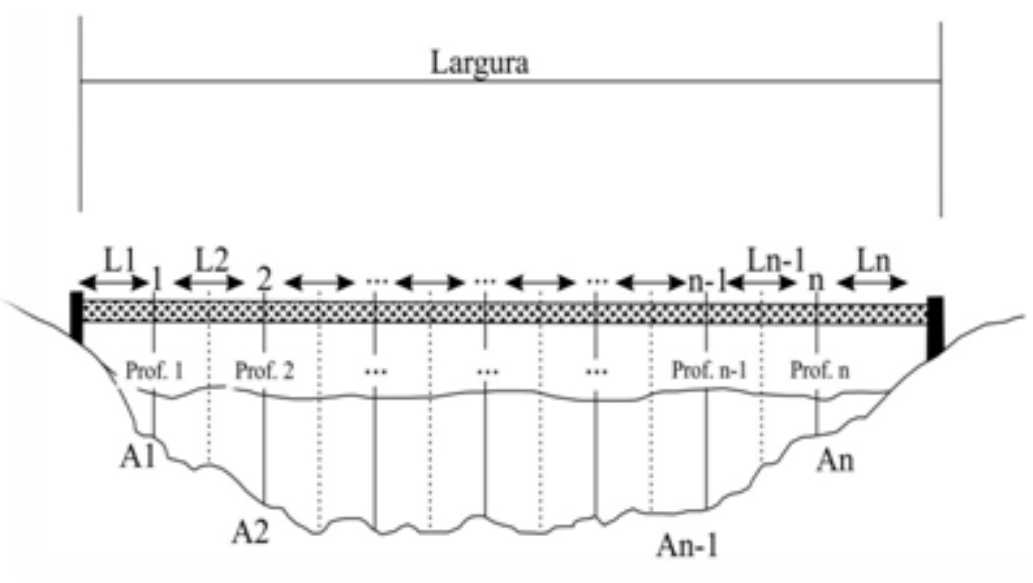

Figura 2. Definição das seções transversais para medição da vazão.

A coleta de dados pelo equipamento foi instantânea, contudo houve a necessidade de inserir previamente as características de profundidade e de largura em cada vertical. O modo de coleta de dados foi a seção média e, como esse equipamento possui o tratamento estatístico automático, ou seja, foi previamente definido um desvio padrão máximo na média dos dados coletados de 0,01 , as repetições foram realizadas apenas quando o equipamento solicitou uma nova tomada de dados.

Para estimar o incremento de vazão no ribeirão Maringá proporcionado por tributários e lançamentos de efluentes localizados em área de difícil acesso foi calculado o incremento linear, conforme descrito por Von Sperling (2007). Para o balanço de vazão, lançou-se mão do modelo matemático QUAL 2E.

No período de estudo, a vazão da Estação de Tratamento de Efluente (ETE) lançado no córrego Mandacaru foi fornecida pela Companhia de Saneamento do Paraná (SANEPAR).

\subsection{Quantificação das Cargas Poluidoras}


Fonrum Ambiental

da Alta Paulista
ISSN 1980-0827

Volume 9, Número 2, 2013

Bacias Hidrográficas, Planejamento e

Gestão dos Recursos Hídricos

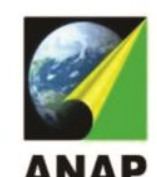

ANAP

A quantificação da carga de poluentes foi determinada por meio do método descrito em Von Sperling (2007), que consiste no produto dos valores de concentração de poluentes, determinados para cada ponto do trecho estudado pela vazão do rio. A carga poluente foi determinada para os parâmetros de qualidade supracitados.

\section{RESULTADOS}

\subsection{Precipitação Pluviométrica e Parâmetros de qualidade e}

A partir dos resultados apresentados na Figura 3 foi possível observar os padrões de precipitação nos meses estudados.

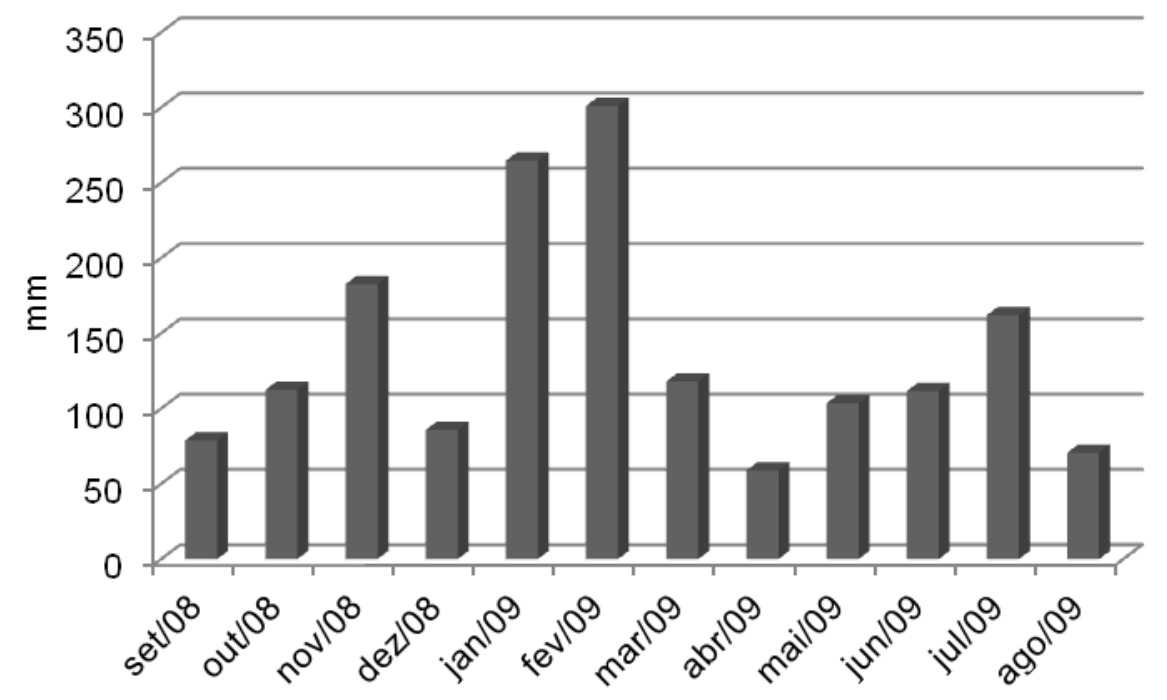

Figura 3. Precipitação mensal ocorrida durante o período de estudo.

Analisando a Figura 3, notou-se que os maiores valores de precipitação foram encontrados nos meses de novembro de 2008, janeiro, fevereiro e julho de 2010 (182,7 mm; 267,7,3 mm e 301,1 mm e 162,1, respectivamente). Os menores valores de precipitação média ocorreram em setembro $(78,8 \mathrm{~mm})$, dezembro $(85,3 \mathrm{~mm})$ de 2008 , abril $(58,9 \mathrm{~mm})$ e agosto $(70,6 \mathrm{~mm})$ de 2010 . Tais resultados apontam para uma grande aticipicidade do regime pluviométrico durante o período de estudo tendo em vista a classificação climática do local. 
Com vistas a avaliar a influência da precipitação nos resultados obtidos, na Tabela 1 são apresentadas as ocorrências de precipitação pluviométrica $(\mathrm{mm})$, no momento e nos dias que antecederam as medições hidráulicas e a coleta de amostras para as análises físico-químicas e biológicas.

Tabela 1. Valores de Precipitação pluviométrica $(\mathrm{mm})$ antecedentes aos trabalhos em campo

\begin{tabular}{lcccc}
\hline Campanha & Coleta & $24 \mathrm{~h}$ & $48 \mathrm{~h}$ & $72 \mathrm{~h}$ \\
\hline Setembro/08 & 0 & 0 & 5,8 & 39,2 \\
Outubro/08 & 0 & 0 & 15,9 & 2,6 \\
Dezembro/08 & 0,4 & 11,1 & 0 & 0 \\
Fevereiro/09 & 18,5 & 1 & 0 & 4,8 \\
Abril/09 & 19,9 & 39 & 0 & 0 \\
Maio/09 & 0 & 0 & 0 & 30,1 \\
Agosto/09 & 0 & 1,5 & 0,1 & 1 \\
\hline
\end{tabular}

A Tabela 2 apresenta um resumo dos valores obtidos para os parâmetros de qualidade de água analisados. A tabela mostra os valores de cada parâmetro na forma dos seus valores médios obtidos ao longo de todo o período de coleta.

Tabela 2. Valores dos parâmetros de qualidade

\begin{tabular}{cccccc}
\hline & $\begin{array}{c}\mathrm{ST} \\
(\mathrm{mg} / \mathrm{L})\end{array}$ & $\begin{array}{c}\mathrm{DBO} \\
(\mathrm{mg} / \mathrm{L})\end{array}$ & $\begin{array}{c}\mathrm{NO}_{3}{ }^{-} \\
\mathrm{mg} / \mathrm{L})\end{array}$ & $\begin{array}{c}\mathrm{FT} \\
(\mathrm{mg} / \mathrm{L})\end{array}$ & $\begin{array}{c}\mathrm{CT} \\
(\mathrm{UFC} / 100 \mathrm{~mL})\end{array}$ \\
\hline P1 & 175,1 & 1,270 & 4,292 & 0,266 & 4443 \\
P2 & 124,6 & 1,383 & 1,583 & 0,155 & 207 \\
P3 & 188,8 & 1,385 & 4,000 & 0,191 & 307 \\
P4 & 205,4 & 7,201 & 2,575 & 2,373 & 17789 \\
P5 & 151,5 & 4,117 & 4,158 & 1,079 & 3043 \\
P6 & 169,9 & 6,504 & 3,767 & 1,373 & 3571 \\
\hline
\end{tabular}

\subsection{Vazão}


A Tabela 3 apresenta os valores de vazões obtidos em campo e aqueles obtidos por meio do cálculo do incremento linear, utilizando o modelo QUAL2E. A Figura 4 mostra os perfis das vazões do ribeirão Maringá ao longo do período de monitoramento.

Tabela 3. Vazões $\left(\mathrm{m}^{3} / \mathrm{s}\right)$ para os pontos de monitoramento durante o período de estudo

\begin{tabular}{lcccccc}
\hline \multicolumn{1}{c}{ Mês } & P1 & P2 & P3 & P4 & P5 & P6 \\
\hline Setembro/08 & 0,219 & 0,102 & 0,205 & 0,687 & 0,813 & 0,909 \\
Outubro/08 & 0,158 & 0,081 & 0,346 & 0,779 & 0,855 & 0,914 \\
Dezembro/08 & 0,194 & 0,095 & 0,190 & 0,771 & 1,061 & 1,352 \\
Fevereiro/09 & 0,334 & 0,129 & 0,366 & 1,222 & 1,391 & 1,510 \\
Abril/09 & 0,187 & 0,111 & 0,189 & 0,798 & 0,978 & 1,264 \\
Maio/09 & 0,125 & 0,102 & 0,285 & 0,776 & 0,896 & 0,987 \\
Agosto/09 & 0,182 & 0,102 & 0,178 & 0,762 & 0,932 & 1,063 \\
\hline
\end{tabular}

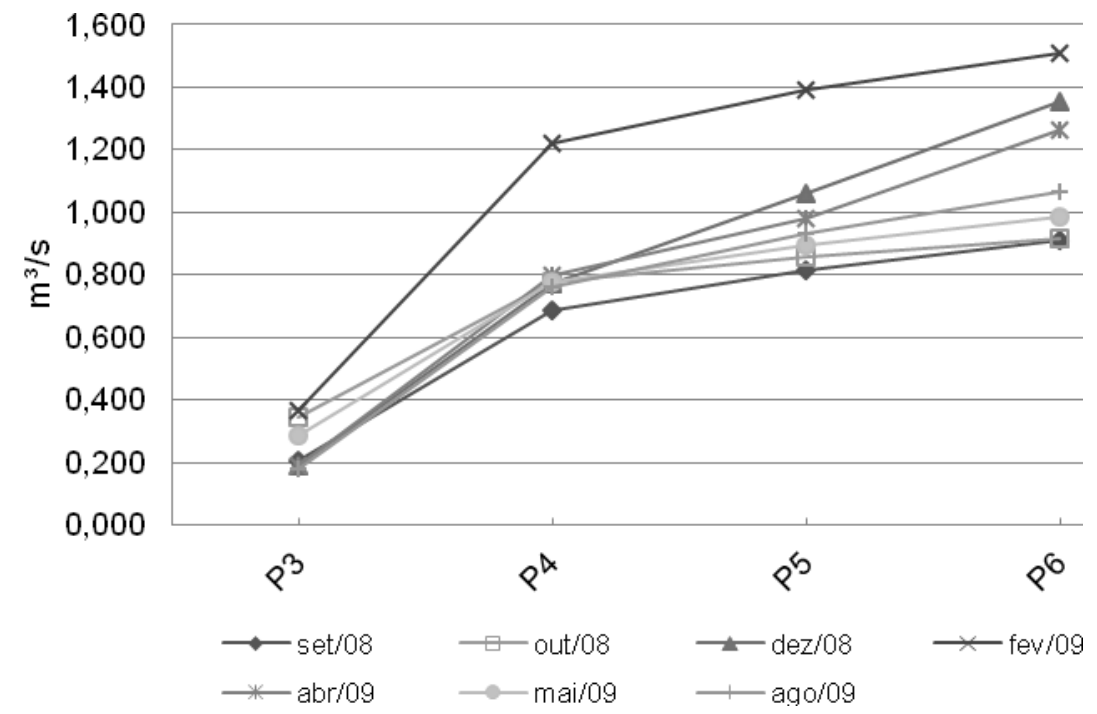

Figura 4. Perfil de vazão do ribeirão Maringá.

Por meio da modelagem matemática foi possível simular os valores de vazão para o ponto 3, localizado no ribeirão Maringá antes da contribuição dos tributários córregos Romeira e Mandacaru, e para o ponto 5, localizado após o córrego das Rosas, de modo muito satisfatório. Assim, foi possível construir todo o perfil de vazão do ribeirão Maringá. Os meses de fevereiro de 2009 e setembro de 2008 foram aqueles que apresentaram os 
valores máximos e mínimos de vazão, respectivamente, caracterizando os períodos de chuvas intensas e estiagem nessa bacia.

No trecho representado pelo ponto 1, localizado no córrego Mandacaru à montante dos despejos da estação de tratamento de esgotos (ETE) do município, as vazões medidas oscilaram entre os valores de $0,334 \mathrm{~m}^{3} / \mathrm{s}$ e $0,125 \mathrm{~m}^{3} / \mathrm{s}$, nos meses fevereiro e maio de 2010, respectivamente, não coincidindo o valor mínimo com o registrado como mês de estiagem para o ribeirão Maringá. De modo semelhante, o trecho representado pelo ponto 2, localizado no córrego Romeira, a vazão mínima foi registrada em outubro de $2008\left(0,081 \mathrm{~m}^{3} / \mathrm{s}\right)$.

A interpretação da análise da vazão incremental dos tributários se fez importante, pois seus respectivos fluxos hídricos contribuíram para a manutenção do fluxo de água do ribeirão Maringá em períodos críticos de pouca precipitação, garantindo a manutenção das funções ecológicas do corpo d'água.

\subsection{Cargas Poluidoras}

As figuras a seguir apresentam os valores das cargas de sólidos totais, DBO, nitrato, coliforme termotolerantes e fósforo total, calculadas para as sete campanhas de monitoramento.

De maneira geral, foi possível observar por meio da Figura 5 uma alta carga de sólidos presentes nas águas do ribeirão Maringá, principalmente nos trechos dos pontos 4, 5 e 6. Como a carga sólida de $\mathrm{P} 1$ é relativamente baixa, pode-se dizer que a o lançamento de efluente pela estação de tratamento de esgotos sanitários do município contribuiu para os acumulados apresentados nos trechos dos pontos P4 e P5. No trecho correspondente ao ponto 6 verificou-se em campo que os despejos oriundos de um pesqueiro e os despejos clandestinos de esgotos sanitários no córrego das Rosas, tributário do ribeirão Maringá, podem ter proporcionado a elevação de carga nesse ponto.

Em relação à sazonalidade, constatou-se uma variação da carga de sólidos de modo mais evidente nos tributários (P1 e P2), no ponto de cabeceira (P3) e no P4, apresentando valores de pico nos meses chuvosos e valores mínimos na época de 
estiagem. A erosão devido à falta de mata marginal pode ser apontadas como uma das principais fontes.

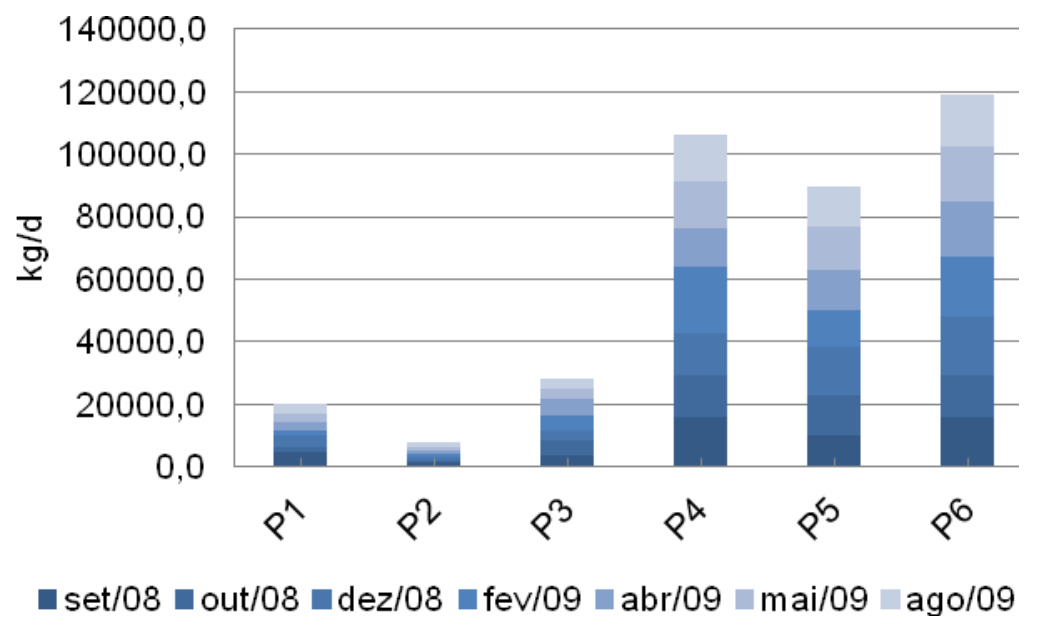

Figura 5. Contribuição da carga de sólidos totais durante o período de estudo.

Em relação à carga de DBO presente nos trechos estudados, por meio da Figura 6 pode-se observar nitidamente que, o trecho representado pelo ponto 4 e pelo ponto 6 apresentou cargas muito superiores aos demais trechos em todo o período de monitoramento. Isso vem ratificar que as principais fontes de matéria orgânica para o trecho é o despejo da ETE e do pesqueiro. Esses efluentes são responsáveis por uma elevada carga poluente nos cursos d'água. Suas cargas orgânicas bem como as grandes quantidades de agentes microbiológicos - bactérias e vírus - descarregados com as águas residuárias constituem uma ameaça para a saúde da população (Figura 7). 


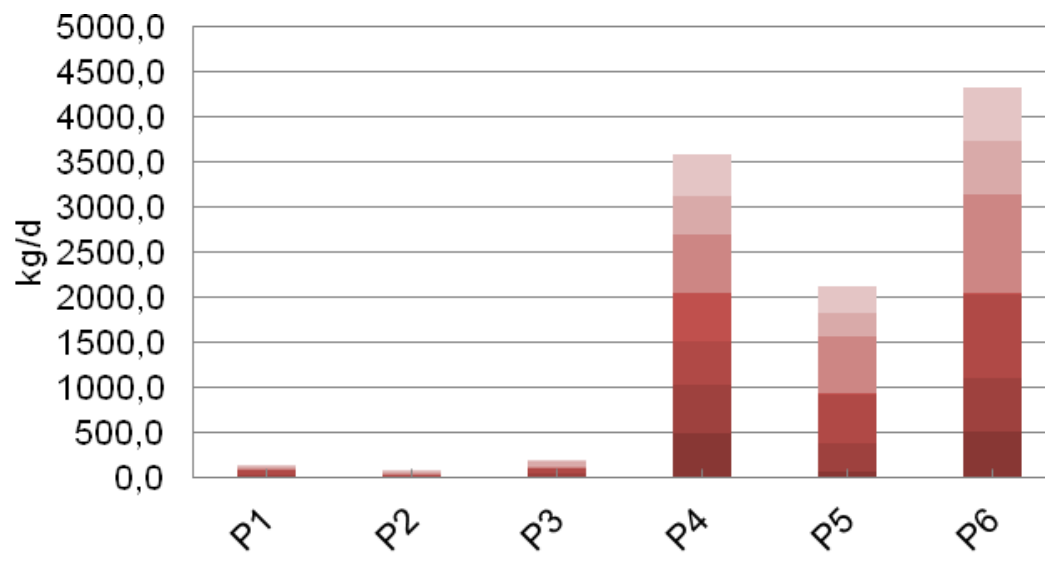

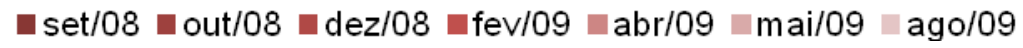

Figura 6. Contribuição da carga de DBO.

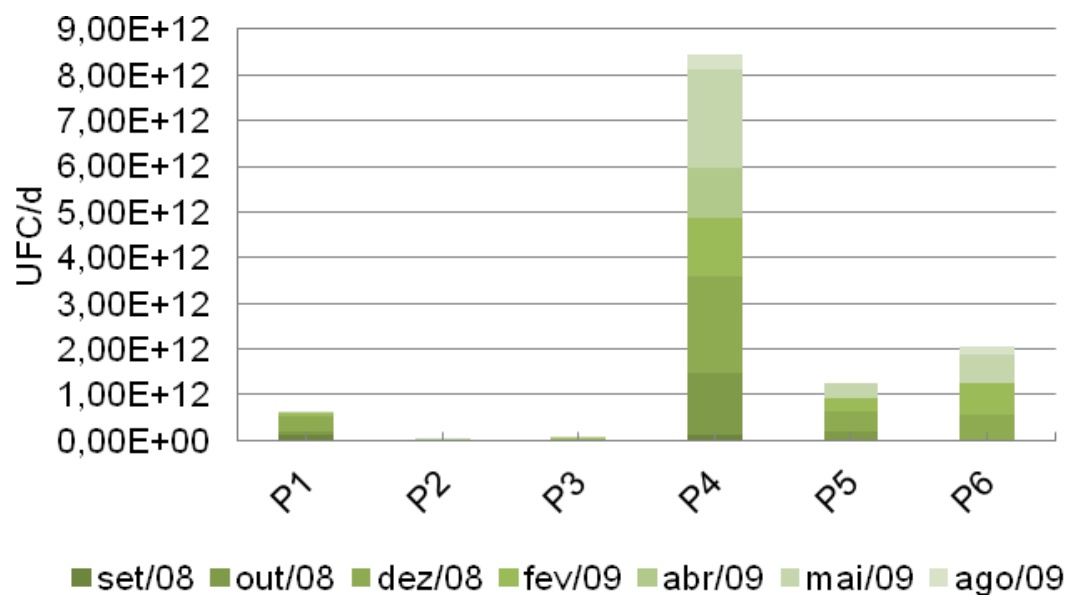

Figura 7. Contribuição da carga de coliformes termotolerantes

A variação da carga de fósforo total nos trechos estudados está apresentada na Figura 8. Apesar de terem sido determinadas concentrações de fósforo muito acima dos limites exigidos pela legislação vigente (Resolução CONAMA ํ357/2005), considerando o enquadramento dos cursos d' água, esse foi o parâmetro que apresentou a menor carga poluidora em comparação com todos os outros parâmetros que tiveram suas cargas calculadas. Mesmo assim, as cargas de fósforo aportadas ao corpo receptor hídrico foram bem altas, chegando a um máximo de $536,9 \mathrm{~kg} / \mathrm{d}$ no mês de outubro de 2008 , no trecho representado pelo ponto 4 . 


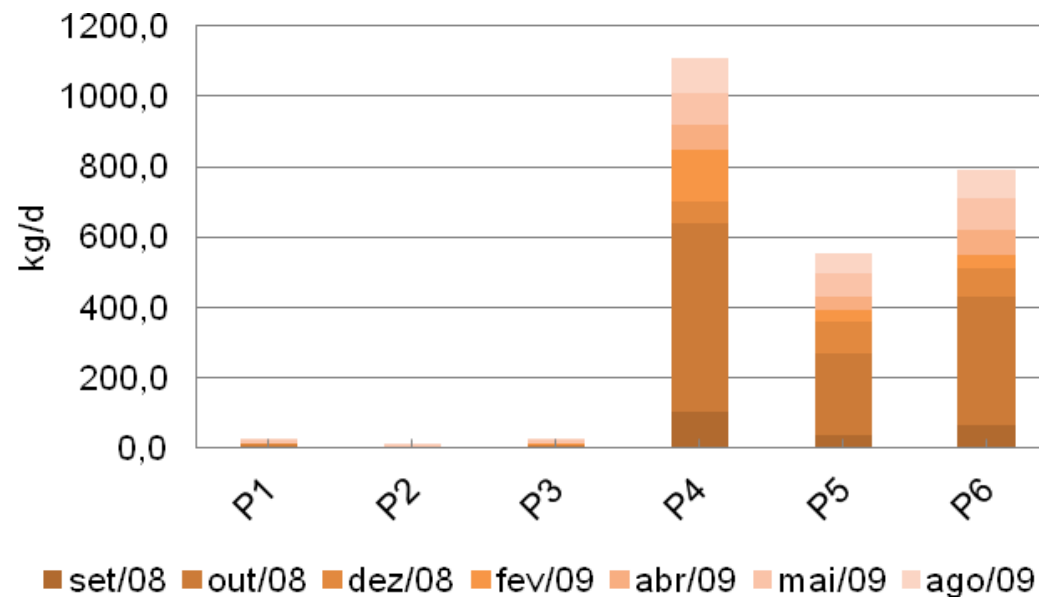

Figura 8. Contribuição da carga de fósforo total.

Considerando que a presença de nitrato em corpos hídricos indica poluição remota, a Figura 9 mostra que há fontes de poluição por toda a bacia, sendo que os menores valores de carga foram identificados no trecho referente ao ponto 2, ponto sobre influência da área rural. Tal análise permite dizer que a área urbana e industrial existentes na cabeceira de drenagem da bacia é aquela que mais influencia as condições de qualidade das águas dos corpos hídricos da bacia.

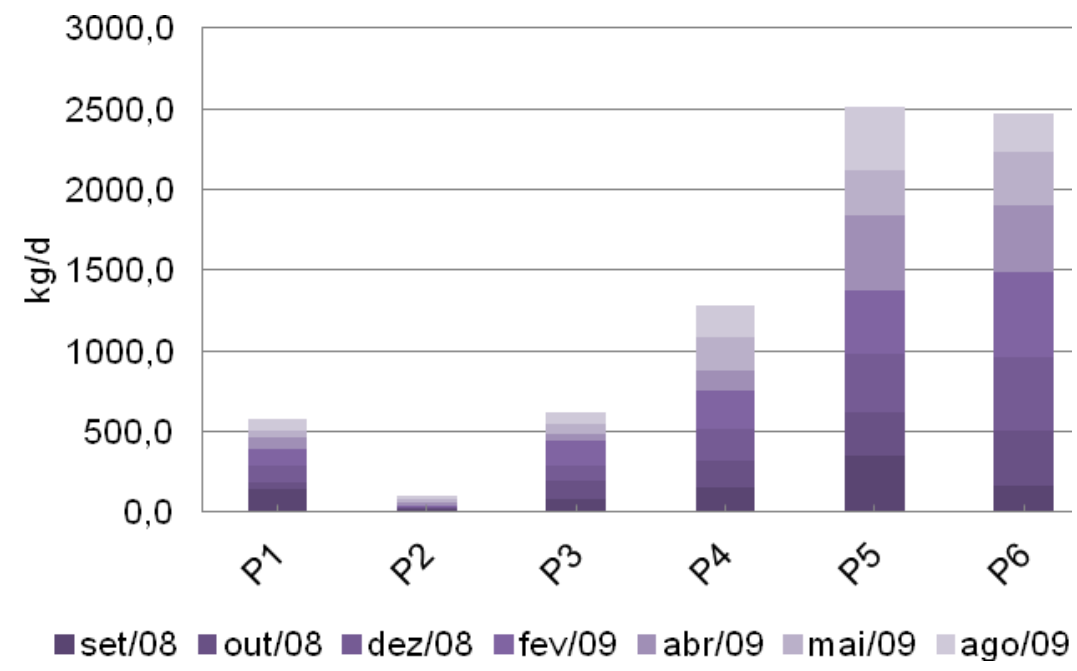

Figura 9. Contribuição da carga de nitrato. 


\section{S Fórum Ambiental \\ da Alta Paulista

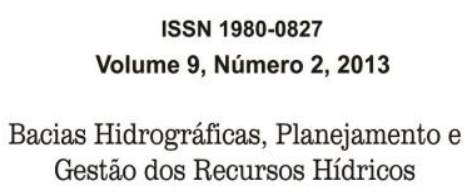

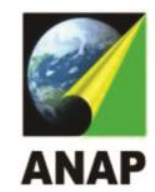

Por meio dos valores de cargas poluidoras obtidos pode-se observar que o ribeirão Maringá vem recebendo um enorme aporte diário, tanto de sólidos quanto de matéria orgânica e nutrientes, provenientes de diversas fontes, as quais podem ser atribuídas principalmente aos despejos domésticos e industriais. Essa contribuição se agrava em períodos chuvosos em que a área rural da bacia passa contribuir por meio do escoamento superficial. As chuvas contribuem para o aumento da vazão do mesmo, o que eleva consideravelmente a carga de poluentes.

\section{CONSIDERAÇÕES FINAIS}

No que diz respeito à quantificação das cargas poluidoras, estas apresentaram valores altíssimos para os cinco parâmetros analisados. Esses valores evidenciam que a poluição originada pelo tratamento não efetivo dos esgotos do município, do lançamento clandestino de esgotos, da atividade agropecuária, entre outras fontes de poluição provenientes das áreas urbanas, rurais e industriais situadas na bacia, estão contribuindo para a degradação e redução da qualidade da água.

Dessa forma, conclui-se que o ecossistema aquático da bacia do ribeirão Maringá está seriamente comprometido e a grande preocupação gerada com os resultados obtidos neste trabalho volta-se para o rio Pirapó, aceptor das águas do ribeirão. Para evitar maiores e futuros prejuízos a esse corpo hídrico deve-se intensificar a fiscalização e o monitoramento da bacia hidrográfica, assim como elaborar um planejamento ambiental de uso e ocupação do solo ao redor da bacia para diminuir os impactos das atividades antrópicas que possam vir a prejudicar o manancial, com o intuito não só de manter a qualidade da água, mas a integridade desse ecossistema.

\section{REFERÊNCIAS}

APHA. American Public Health Association. Standard methods for the examination of water and wastewater. Washington, D.C, 1998. 
BIAZIN, C. P. Concentração de sedimentos em suspensão no ribeirão Maringá, como um indicador geoambiental. 2003. Trabalho de conclusão de curso (Graduação em Geografia) - Departamento de Geografia, Universidade Estadual de Maringá, Maringá, 2003.

BORSATO, F. H.; MARTONI, A. M. Estudo da fisiografia das bacias hidrográficas urbanas no município de maringá - estado do paraná. Acta Scientiarum Human and Social Sciences, v.26, n.2, p.273-285, 2004.

BRASIL. Ministério do Meio Ambiente Conselho Nacional do Meio Ambiente. Resolução no. 357, de 17 de março de 2005. Dispõe sobre a classificação dos corpos de água e diretrizes ambientais para o seu enquadramento, bem como estabelece as condições e padrões de lançamento de efluentes, e dá outras providências. Brasília, 2005.

COELHO, A. R. Dinâmica fluvial e qualidade de água da bacia de drenagem do ribeirão maringá: contribuição para o planejamento e gestão ambiental. 2007. 139p. Dissertação (Mestrado em Geografia) - Departamento de Geografia, Universidade Estadual de Maringá, Maringá.

PARANÁ. Superintendência de Desenvolvimento dos Recursos Hídricos e Saneamento Ambiental. Monitoramento da qualidade das águas. Curitiba, 2007

PERUÇO, J. D. Identificação das principais fontes poluidoras de afluentes da bacia do alto rio Pirapó. 2004. Dissertação (Mestrado em Engenharia Química) Departamento de Engenharia Química, Universidade Estadual de Maringá, Maringá.

SALA, M. G; GASPARETTO, N. V. L. Fragilidade ambiental dos solos em bacias hidrográficas de pequena ordem: o caso da bacia do ribeirão Maringá - PR. Boletim de Geografia, v.28, n.2, p.113-126, 2010.

SCHNEIDER, R. M.; FREIRE, R., COSSICH, E. S.; SOARES, P. F; FREITAS, F. H.; TAVARES, C. R. G. Estudo da influencia do uso e ocupação do solo na qualidade da água de dois córregos da bacia hidrográfica do rio Pirapó. Acta Scientiarum. Technology, v.33, p.295-303, 2011.

SOARES, P. F. Projeto e avaliação de desempenho de redes de monitoramento de qualidade da água utilizando o conceito de entropia. 2001. 242p. Tese (Doutorado em Engenharia Hidráulica) - Departamento de Engenharia Civil, Universidade de São Paulo.

VON SPERLING, M. Estudos e modelagem da qualidade da água de rio, 1. ed. Belo Horizonte: Departamento de Engenharia Sanitária e Ambiental, Universidade Federal de Minas Gerais, 2007. 588 p. (Princípios do tratamento biológico de águas residuárias, v. 7) 